\title{
ARBORIZAÇÃO DE VINTE QUARTEIRÕES AMOSTRADOS NA REGIÃO CENTRAL DE SANTA CRUZ DO SUL- RS
}

\section{RESUMO}

\author{
Deivid Ismael Kern ${ }^{1}$; José Antônio Kroeff Schmitz ${ }^{2}$;
}

O presente trabalho visou diagnosticar a arborização urbana da região central de Santa cruz do Sul - RS. Adicionalmente, o trabalho também propõe avaliar o possível aproveitamento da produção de essências florestais municipal na manutenção e aumento da qualidade do ambiente urbano. A metodologia do trabalho consistiu no levantamento quali-quantitativo dos indivíduos presentes em 20 quadras da região central, e das essências florestais produzidas no horto municipal. Os resultados do levantamento da produção arbórea revelaram produtividade de 31.170 mudas, divididas em 26 famílias e 57 espécies, 36 (62,6\%) nativas e 21 (37,4\%) espécies exóticas. Ao contrário do que é produzido, o ambiente urbano diagnosticado revelou a presença de um número maior de espécies exóticas (91,1\%). Em 20 quadras foram registrados 1.409 indivíduos distribuídos em 26 famílias e 43 espécies, 14 nativas e 29 exóticas. Apenas cinco espécies foram consideradas abundantes: Lagerstroemia indica, Ligustrum lucidum, Jacaranda mimosaefolia, Tipuana tipu e Senna macranthera, as duas primeiras superaram o limite de 15\% de indivíduos por espécie. Este alto predomínio de espécies exóticas indicam a necessidade de um melhor aproveitamento da produção do Horto florestal municipal, para fins de re-planejamento e aumento da qualidade da vegetação no ambiente urbano de Santa Cruz do Sul. Palavras-chave: Ambiente urbano; essências florestais; espécies nativas; espécies exóticas; qualidade ambiental.

\section{AFFORESTATION SAMPLED IN TWENTY BLOCKS IN CENTRAL REGION OF SANTA CRUZ DO SUL- RS}

\section{ABSTRACT}

This study Aimed to diagnose the urban trees in the central region of Santa Cruz do Sul - RS. Additionally, the paper also proposes to evaluate the possible utilization of the production of forest tree species in maintaining and enhancing the quality of urban environment. The methodology of the study consisted of qualitative and quantitative survey of individuals present in 20 blocks of the central region, and also forest species produced in the municipal horto. The survey results revealed the production yield of 31.170 tree seedlings, divided into 26 families and 57 species, 36 (62,6\%) native and 21 (37,4\%) exotic species. Contrary to what is generated, the urban environment diagnosis revealed the presence of more exotic species (91,1\%). In 20 blocks were recorded 1.409 individuals in 26 families and 43 species, 14 native and 29 exotic. Only five species were abundant: Lagerstroemia indica, Ligustrum lucidum, Jacaranda mimosaefolia, Tipuana tipu and Senna macranthera the first two exceeded the limit of $15 \%$ of individuals per species. This high prevalence of exotic species indicate the need for a better utilization of the production forest of the Garden city, for the purpose of re-planning and increase the quality of the vegetation in the urban environment of Santa Cruz do Sul.

Keywords: Urban environment; forest species; native species; exotic species; environmental quality.

\footnotetext{
${ }^{1}$ Biólogo, Tecnólogo em Agropecuária: Horticultura, Mestre em Tecnologia Ambiental - UNISC, Universidade de Santa Cruz do Sul, Avenida Independência no 2293, 96815-900, Santa Cruz do Sul/RS. deividkern@gmail.com.

2 Engenheiro Agrônomo, Dr. Em Ciências do Solo - UFRGS, Universidade Estadual do Rio Grande do Sul - Centro Regional V, Avenida Independência no 2824, 96816-000, Santa Cruz do Sul/RS. jose-schmitz@uergs.edu.br.

${ }^{3}$ recebido em 25.05.2012 e aceito para publicação em 15.09.2013
} 
Conceitua-se “arborização urbana” como sendo toda cobertura vegetal de porte arbóreo presente nas cidades e ocupando fundamentalmente três espaços distintos: áreas livres de uso público e potencialmente coletivo, áreas livres particulares e toda a vegetação que acompanha a malha viária. Consiste principalmente da presença de árvores de porte em praças, parques e calçadas, sendo considerada parte integrante da gestão urbana, principalmente por possuir relevante importância social e ecológica (MARTINS; MAIA; BRITO, 2007).

Atualmente, a arborização urbana é tema científico de grande importância prática e tem gradualmente conquistado espaços nos mais diferentes meios de comunicação especializada, tais como teses, dissertações, monografias e periódicos. A praticidade do tema esta relacionada às influências que a arborização causa ao ambiente urbano, impactando diretamente o mercado imobiliário (através da flutuação de preços de terrenos e imóveis), saúde pública (principalmente pela presença de espécies alergênicas, tóxicas e com espinhos) e bem estar em geral (redução da poluição do ar em ambientes urbanos, fornecimento de sombra e frutos para avifauna epopulação) (CORRÊA, 2006).

Neste contexto, a arborização das cidades assume um papel importantíssimo na qualidade de vida e bem estar da população urbana, representando um dos elos de ligação do homem com a natureza, e contribuindo de maneira significativa como elemento essencial para o equilíbrio do ambiente artificial onde se está inserida. Sendo assim, ela não só assume papeis relacionados ao embelezamento do ambiente, como também tem a capacidade de desempenhar funções ecológicas de grande relevância.

De acordo com Graziano (1994), apud Dantas e Souza (2004), as funções que a vegetação urbana desempenha nas cidades podem ser divididas também em três aspectos diferentes: do ponto de vista fisiológico, a arborização melhora o ambiente urbano através da capacidade de produzir sombra e filtrar ruídos, amenizando a poluição sonora; melhora a qualidade do ar, aumentando o teor de oxigênio e umidade, além de absorver o gás carbônico; ameniza a temperatura, trazendo bem aqueles que podem usufruir da sua presença ou de sua proximidade.

Do ponto de vista estético, contribuem através das qualidades plásticas, como cor, forma e textura de cada parte visível de seus componentes, emoldurando ruas e avenidas e contribuindo para reduzir os efeitos agressivos das construções que dominam a paisagem urbana, devido a sua capacidade de integrar os vários componentes do sistema. Do ponto de vista psicológico, a vegetação é capaz de criar certo grau de satisfação ao homem, principalmente quando este está em contato com a mesma e com o ambiente que ela é capaz de criar (DANTAS; SOUZA, 2004).

Santos et al. (1994) afirmam que as árvores, além de desempenharem a sua função fundamental, contribuem também para: retenção de poeiras e pó, manutenção do equilíbrio no gradiente térmico, contenção de terras em morros, encostas e obras de engenharia, barreira contra ruídos, manutenção da umidade do ar, retenção e condução de água no solo, além da ambientação adequada à permanência e expansão da avifauna urbana, conferindo formas vivas e alegres no acinzentado da massa urbana e melhoram a saúde física e mental da população.

Deivid Ismael Kern e José Antônio Kroeff Schmitz 
De acordo com Dantas e Souza (2004), além de promover o conforto ambiental e diminuir os efeitos do ambiente hostil das cidades, a função ecológica que a arborização desempenha é fundamental, principalmente quando se trata em estender e manter a identidade biológica sobre determinada região impactada pelo ambiente urbano.

Devido a grande diversidade de funções que esta vegetação desempenha nos ambientes urbanos, fazem-se necessários adotar critérios rígidos na seleção de espécies a serem utilizadas, tanto com relação ao ecossistema local, como em relação ao público que convive nestes espaços. O desempenho da arborização urbana é reflexo, portanto, da forma com que se faz o seu planejamento, desde a produção em viveiros até o plantio e aproveitamento nas cidades (BIONDI; LEAL, 2008).

Atualmente tem havido uma grande preocupação com relação à biodiversidade em ambientes urbanos. Em alguns casos as preocupações com relação à diversificação levam a produção inadequada de espécies tóxicas e espécies invasoras incompatíveis com o ambiente urbano e com o homem. Sendo assim, as características das espécies que irão compor a cobertura vegetal pública de uma cidade devem ser criteriosamente analisadas, antes mesmo de serem produzidas em viveiros (BIONDI; LEAL, 2008).

Na maioria das cidades brasileiras observam-se o negligenciamento histórico da arborização urbana dentro do planejamento e elaboração dos planos diretores das cidades, em que a mesma é apresentada de forma meramente ornamental e sem função ambiental relevante. O poder público por este fato tem sido paulatinamente cobrado pelas organizações civis, e tem se visto a reconsiderar na sua conceituação da importância da arborização dentro sistema urbano (BRUN et al., 2008).

Conforme MMA (2006), espécies exóticas invasoras são consideradas a segunda maior causa de extinção de espécies no planeta, afetando diretamente a biodiversidade, a economia e a saúde pública.

Além da problemática do aproveitamento de espécies inadequadas ao ambiente urbano, seja pela potancialidade tóxica ou alergênica, ou por serem exóticas invasoras e acarretarem em risco potencial a biodiversidade regional, outros problemas como aproveitamento de espécies de porte inadequado também são comuns. Este problema é visto através da competição de árvores com outros elementos urbanos como fiações elétricas, encanamentos, calhas, calçamentos, muros, postes de iluminação, etc (RODRIGUEZ et al., 2002).

Diante dessa problemática, o presente trabalho visou diagnosticar de maneira quali-quantitativa, através da aplicação de inventário, aspectos importantes relacionados à composição da arborização de vias públicas, amostradas na região central do perímetro urbano de Santa Cruz do Sul, RS. Além disso, o levantamento da produção de essências florestais pelo horto municipal foi realizado com a finalidade de investigar as potencialidades para atender as demandas de espécies arbóreas necessárias ao aproveitamento na arborização e gestão do ambiente urbano da região. 


\section{Caracterização da área de estudo}

Santa Cruz do Sul está localizada na região conhecida como Vale do Rio Pardo, depressão central do estado, encosta inferior do nordeste do Rio Grande do Sul, estando distante aproximadamente $155 \mathrm{~km}$ da capital Porto Alegre. Suas coordenadas geográficas correspondem a 2943'59” de Latitude Sul e 52²4’52” de Longitude Oeste. A região apresenta altitude média de $122 \mathrm{~m}$ acima do nível do mar e clima subtropical temperado, com temperaturas médias de $19^{\circ} \mathrm{C}$, máximas de $42^{\circ} \mathrm{C}$ e mínimas de $5^{\circ} \mathrm{C}$. As chuvas ocorrem em médias de 100 a 126 dias ao ano, com índice de precipitação variando de 1300 a 1800 mm. O município possui área total de 794,49 km², sendo 156,96 km² de área urbana e 637,53 km² de área rural. Possui população estimada em 115.930 habitantes (IBGE, 2007). O produto interno bruto é de US\$ 1.356.221.815,83 bilhões e uma renda per capita de U\$ 12.834,02, reflexo principalmente da atividade de indústrias fumageiras na região (PREFEITURA MUNICIPAL DE SANTA CRUZ DO SUL, 2006).

O centro da cidade conta com quadras de característica urbanística similar, com pouca variação de tamanho e grande similaridade arquitetônica, exceto quando próximas dos bairros, localizados nas periferias da cidade.

A região central é provida de uma Catedral estilo neo-gótico, com jardim localizado ao seu entorno, e praças plenamente arborizadas. A cidade também conta com um túnel verde que contempla toda sua rua de acesso principal, Marechal Floriano. O túnel, constituído por tipuanas (Tipuana tipu), com idade aproximada de 40 anos, abriga grande parte dos pontos comerciais mais procurados da mesma, estendendo-se por toda a região do centro da cidade.

O município é também provido de uma expressiva vegetação nativa em seu entorno, denominada de “cinturão verde”, a qual é considerada área de conservação ambiental e uso restrito, com finalidades de preservação da flora e fauna da região e conservação de importantes nascentes.

\section{Metodologia de amostragem}

Para esse trabalho adotou-se uma metodologia de amostragem estratificada, levando-se em conta principalmente a localização das quadras e sua similaridade urbanística, em termos de tamanho, formato e sua distribuição na área de estudo. A coleta de dados foi realizada entre os meses de janeiro a abril de 2009, através da aplicação de inventário tipo censo em 20 quadras da região central da cidade. A escolha das quadras está relacionada com os objetivos do trabalho, uma vez que possibilita conhecer o patrimônio arbóreo, diagnosticar a gestão urbana na arborização, visualizar os efeitos e influências antropogênicas de maior e menor intensidade sobre a vegetação, e propor intervenções no aproveitamento e aplicação da produção de essências florestais nas vias públicas. Para o inventariamento da arborização, indivíduos presentes nas 20 quadras do perímetro urbano, vivos ou mortos, mas ainda de pé, e com altura mínima de 1,30 m em relação ao solo foram considerados.

As espécies amostradas nos passeios públicos e as mudas produzidas pelo horto florestal municipal também foram identificadas e quantificadas até o menor nível taxonômico possível. As identificações das espécies foram feitas com o auxílio de chaves 
de identificação botânica de Putzke (2003), Sobral et al (2006), auxiliada por bibliografias botânicas de Vidal e Vidal (2001), Backes e Irgan (2002) e (2004) e Dantas e Souza (2001). O sistema de classificação APG III (2009) também foi utilizado na revisão de possíveis atualizações taxonômicas.

Quanto à origem fitogeográfica, foram consideradas como espécies nativas as originárias de formações vegetais ocorrentes nos diferentes ecossistemas do Brasil. As espécies que ocorrem em outros ecossistemas diferentes dos que compõem a flora brasileira foram consideradas exóticas.
A diversidade foi estimada através da aplicação do índice de Shannon-Wiener em Shannon e Weaver (1949) apud Coelho (2000) com auxílio da aplicação dos pacotes estatísticos presentes no programa PAST ver. 2.02 de 2010.

A avaliação da produtividade de mudas foi feita através da separação de grupos de essências que superaram a média aritimética de indivíduos produzidos por espécie e aqueles que estiveram abaixo da metade da referida média.

\section{RESULTADOS E DISCUSSÕES}

\section{Resultado do levantamento da arborização urbana nas 20 quadras}

Na área amostrada foram encontrados 1.409 indivíduos divididos em 43 espécies, sendo 14 nativas do Brasil e 29 exóticas, todas distribuídas em 26 famílias botânicas. Cinco espécies apresentaram o maior número de indivíduos por espécies, e superaram a média aritmética geral $(31,3)$ de distribuição de indivíduos por espécie, sendo representadas por: Extremosa (Lagerstroemia indica) (735 indivíduos), Ligustro (Ligustrum lucidum) (219 indivíduos), Jacarandá mimoso (Jacaranda mimosaefolia) (107 indivíduos), Tipuana (Tipuana tipu) (82 indivíduos) e Manduirana (Senna macranthera) (32 indivíduos), correspondendo a 83,4\% (1.175 indivíduos) do total de árvores amostradas (Tabela 1). As espécies Lagerstroemia indica e Ligustrum lucidum foram as que apresentaram com maior prevalência no levantamento, estando presentes em, respectivamente, 52,20 e 15,50\% dos indivíduos encontrados. Estas espécies corresponderam por $67,70 \%$ dos indivíduos amostrados e estiveram fora da freqüência de 15\% de indivíduos por espécie em uma distribuição populacional proposta por Grey e Deneke (1978). Segundo o mesmo autor, valores superiores a 15\% de freqüência em uma distribuição populacional de árvores em ambientes urbanos podem aumentar a probabilidade de ocorrência e disseminação de pragas e doenças. No entanto, ainda é comum ocorrer poucas espécies representando a maioria da população de árvores em ambientes urbanos, que por razões estéticas ou fitossanitáreas são indesejáveis (SILVA, 2000).

Com relação a distribuição de famílias botânicas, Lithraceae, Oleaceae, Bignoniaceae, LeguminosaePapilionoideae e Leguminosae-Mimosoideae foram as mais comuns da amostra, representando $87,3 \%$. A análise da freqüência, de acordo com o centro de origem fitogeográfico de cada espécie, demonstrou que apenas 8,9\% das árvores encontradas em vias públicas são nativas do Brasil, sendo o restante (91,1\%), representadas por exóticas.

Três espécies nativas e frutíferas, como Ingá (Inga marginata Willd) (30), Aroeira vermelha (Schinus terebinthifolius Raddi) (3) e Pitangueira (Eugenia uniflora L) (2), são consideradas interessantes para avifauna local, correspondendo a um total de 2,48\% 
do total de árvores amostradas (Tabela 1). Oito espécies exóticas, Ameixeira (Eriobotrya japonica) (3), Amora (Morus alba L) (3), Citrus (Citrus sp) (4), Goiabeira (Psidium guajava L.) (3), Jambolão (Syzygium euminni) (L.)(1) e Pereira (Pyrus communis L) (6), possuem frutificação evidente, podendo, em determinadas circunstâncias, ser consideradas como fonte alimentar alternativa para avifauna local. Estas espécies corresponderam a 1,42\% do total de indivíduos amostrados.

Sanchonete (2000) e Ruschel e Leite (2002), afirmam que as espécies exóticas, quando presentes em abundância nos sistemas urbanos, afetam diretamente as áreas de conservação natural inseridas dentro do ambiente artificial. Portanto, a presença de espécies nativas dentro da malha viária e próxima de fragmentos pode contribuir significativamente com a conservação da própria fauna regional. Neste caso, aves e insetos atraídos pela oferta de alimentos acabam sendo os principais agentes de perpetuação das espécies. Esta participação da fauna contribui, conseqüentemente, com o equilíbrio do meio ambiente, salvo ocorrência de disseminação inversa, ou seja, de polinização e propagação de sementes de espécies exóticas em ambiente natural.

Algumas espécies ditas como inadequadas por Ruschel e Leite (2002), Santos e Teixeira (2001) e Backes e Irgang (2004), foram encontradas em uma proporção de 16,32\% dos indivíduos amostrados, entre elas estão Ligustro (Ligustrum lucidum W.T.Aiton) com 219 indivíduos e Buxinho (Buxus sempervirens) com 7, ambos considerados espécies alérgicas em época de floração, Leiteiro vermelho (Euphorbia cotinifolia L) com 1 ocorrência, considerada eventualmente tóxica para pedestres, Cinamomo (Melia azedarach L) com 3, ornamental, melífera, mas com frutificação tóxica, Limoeiro (Citrus sp.) com 2 e Paineira (Chorisia speciosa St.Hil) com 1 indivíduo são consideradas inadequadas por possuírem espinhos e acúleos capazes de ferir pedestres (Tabela 1).

Tabela 1. Relação total de espécies florestais encontradas nas 20 quadras de Santa Cruz do Sul, região central, identificadas por nome popular, espécie, família, origem, quantidade e freqüência dos indivíduos amostrados no ano de 2009. Qtd: Quantidade, Freq: Freqüência relativa.

\begin{tabular}{llllll}
\hline Nome popular & Nome científico & Família & Origem (1) & Qtd. & Freq. \\
\hline Acer & Acer negundo L. & Acaraceae & E/Canadá/ EUA & 3 & $0,21 \%$ \\
Ameixa & $\begin{array}{l}\text { Eriobotrya japonica (thunb.) } \\
\text { lindl }\end{array}$ & Rosaceae & E/Japão/China & 3 & $0,21 \%$ \\
Amoreira & Morus alba L. & Moraceae & E/China & 3 & $0,21 \%$ \\
Angico vermelho & Parapiptadenia rigida Brenan. & Leg.-Mimosoideae & N/Brasil & 1 & $0,07 \%$ \\
Araucária & Araucaria heterophylla (Salisb.) & Araucariaceae & E/Ilhas Norfolk & 1 & $0,07 \%$ \\
Aroeira vermelha & Schinus terebinthifolius Raddi & Anacardiaceae & N/Brasil & 3 & $0,21 \%$ \\
Butiá & Butia capitata (Mart.) Becc. & Arecaceae & N/Brasil & 3 & $0,21 \%$ \\
Buxus & Buxus sempervirens L. & Buxaceae & Oriente/China & 7 & $0,50 \%$
\end{tabular}




\begin{tabular}{|c|c|c|c|c|c|}
\hline Canafístula & Peltophorum dubium Taub. & $\begin{array}{l}\text { Leg.- } \\
\text { Caesalpinoideae }\end{array}$ & N/Brasil & 5 & $0,35 \%$ \\
\hline Canela & $\begin{array}{l}\text { Cinnamomum zeylanicum } \\
\text { (Brey). }\end{array}$ & Lauraceae & E/Ceilão & 10 & $0,71 \%$ \\
\hline Cássia-imperial & Cassia fistula $\mathrm{L}$. & $\begin{array}{l}\text { Leg.- } \\
\text { Caesalpinoideae }\end{array}$ & E/Ásia & 3 & $0,21 \%$ \\
\hline Chal-chal & Allophylus edulis (ST Hil.) & Sapindaceae & N/Brasil & 1 & $0,07 \%$ \\
\hline Chapéu de Napo. & $\begin{array}{l}\text { Thevetia peruviana (Pers.) } \\
\text { Schum. }\end{array}$ & Apocinaceae & E/ Am. Central & 1 & $0,07 \%$ \\
\hline Cinamomo & Melia azedarach L. & Meliaceae & E/Austrália & 3 & $0,21 \%$ \\
\hline Cipreste & Juniperus virginiana L. & Cupressaceae & E/EUA & 1 & $0,07 \%$ \\
\hline Citrus & Citrus sp & Rutaceae & E/Ásia & 1 & $0,07 \%$ \\
\hline Extremosa & Lagerstroemia indica $\mathrm{L}$. & Lithraceae & E./China & 735 & $52,2 \%$ \\
\hline Fícus benjamin & Ficus benjamina L. & Moraceae & E/Índia & 15 & $1,1 \%$ \\
\hline Fícus variegato & Ficus benjamina variegata L. & Moraceae & E/Índia & 4 & $0,28 \%$ \\
\hline Goiabeira & Psidium guajava L. & Myrtaceae & E/Am. Trop. & 3 & $0,21 \%$ \\
\hline Hibisco variegado & Hibiscus rosa-sinensis L. & Malvaceae & E/Ásia & 2 & $0,14 \%$ \\
\hline Hibisco vermelho & Hibiscus rosa-sinensis L. & Malvaceae & E/Ásia & 6 & $0,41 \%$ \\
\hline Hiboscus amarelo & Hibiscus rosa-sinensis L. & Malvaceae & E/Ásia & 1 & $0,07 \%$ \\
\hline Ingá & Inga marginata Willd. & Leg.-Mimosoideae & N/Brasil & 30 & $2,1 \%$ \\
\hline Ipê amarelo & $\begin{array}{l}\text { Handroanthus chrysotrichus } \\
\text { (Mart.Ex DC) }\end{array}$ & Bignoniaceae & N/Brasil & 18 & $1,28 \%$ \\
\hline Ipê roxo & $\begin{array}{l}\text { Handroanthus avellanedae Lor. } \\
\text { Ex Griseb }\end{array}$ & Bignoniaceae & N/Brasil & 6 & $0,41 \%$ \\
\hline $\begin{array}{l}\text { Jacarandá } \\
\text { mimoso }\end{array}$ & $\begin{array}{l}\text { Jacaranda mimosaefolia } \\
\text { D.Don }\end{array}$ & Bignoniaceae & E/Argentina & 107 & $7,6 \%$ \\
\hline Jambolão & Syzygium euminni L. & Myrtaceae & E/Ásia & 1 & $0,07 \%$ \\
\hline Laranjeira & Citrus sp & Rutaceae & E/Ásia & 1 & $0,07 \%$ \\
\hline $\begin{array}{l}\text { Leiteiro } \\
\text { Vermelho }\end{array}$ & Euphorbia cotinifolia L. & Euphorbiaceae & E/ Am. Central & 1 & $0,07 \%$ \\
\hline Ligustro & Ligustrum lucidum W.T.Aiton & Oleaceae & E/ Japão & 219 & $15,5 \%$ \\
\hline Limoeiro & Citrus sp & Rutaceae & E/Ásia & 2 & $0,14 \%$ \\
\hline Manduirana & $\begin{array}{l}\text { Senna macranthera (Collad.) } \\
\text { Irwin. }\end{array}$ & Leg.-Mimosoideae & N/Brasil & 32 & $2,27 \%$ \\
\hline Miconia & Miconia sp. & Melastomataceae & N/Brasil & 17 & $1,21 \%$ \\
\hline Paineira & Chorisia speciosa St.Hil. & Malvaceae & N/Brasil & 1 & $0,07 \%$ \\
\hline Palmeira família & Dypsis lutescens H. Wend & Arecaceae & E/África & 1 & $0,07 \%$ \\
\hline Palmeira leque & $\begin{array}{l}\text { Livistona chinesis (Jacq.) R. } \\
\text { Br.ex Mart. }\end{array}$ & Arecaceae & E/Madagascar & 1 & $0,07 \%$ \\
\hline Pata de vaca & Bauhinia variegata $\mathrm{L}$. & $\begin{array}{l}\text { Leg.- } \\
\text { Caesalpinoideae }\end{array}$ & E/Ásia: Himalaia & 7 & $0,50 \%$ \\
\hline Pereira & Pyrus communis L. & Rosaceae & Europa/Ásia & 6 & $0,41 \%$ \\
\hline Pingo d' ouro & Duranta repens L. & Verbenaceae & E/México & 12 & $0,85 \%$ \\
\hline Pinheiro alemão & $\begin{array}{l}\text { Chamaecyparis lawsoniana (A. } \\
\text { Murr.) Parl. }\end{array}$ & Cupressaceae & E/EUA & 1 & $0,07 \%$ \\
\hline Pitanga & Eugenia uniflora L & Myrtaceae & N/Brasil & 2 & $0,14 \%$ \\
\hline Seafortia & $\begin{array}{l}\text { Archontophoenix cunninghamii } \\
\text { H. Wendl. Et Drude }\end{array}$ & Arecaceae & E/Austrália & 20 & $1,42 \%$ \\
\hline Siagrus & Syagrus romanzoffiana & Arecaceae & N/Brasil & 1 & $0,07 \%$ \\
\hline
\end{tabular}


(Cham.) Glassman.

\begin{tabular}{llllrr} 
Sibipiruna & Caesalpinia peltophoroides & Leg.- & N/Brasil & 6 & $0,41 \%$ \\
Tipuana & Bhent & Caesalpinoideae & & 82 & $5,82 \%$ \\
Tuja & Tipuana tipu (Benth.) & Leg.-Papilionoideae & E/Argentina & 20 & $1,42 \%$ \\
Total: & Thuja orientalis L. & Cupressaceae & E/China & 1.409 & $100 \%$ \\
\hline
\end{tabular}

(1) E= Exótica; N= Nativa.

Segundo Santos e Teixera (2001), a arborização urbana também deve gerar conforto à população e não causar problemas, mesmo em casos isolados. A presença de certas características estruturais em determinadas espécies, como espinhos, acúleos e excesso de látex dificulta o manejo, podendo provocar acidentes. Da mesma maneira, princípios alérgicos, principalmente com referência ao pólen, são mais comuns durante a primavera, podendo causar problemas e se manifestar de diferentes formas nas pessoas.

Já as plantas tóxicas devem ser consideradas perigosas principalmente quando em contato com crianças, uma vez que a ingestão de determinadas partes podem trazer graves riscos de intoxicações. Independente de a possibilidade ser baixa e dos fatos já serem conhecidos para algumas famílias e espécies, como é o caso do látex tóxico da grande maioria das Euforbiáceas, a escolha das espécies inadequadas deverá ser sempre evitadas.

Portanto, deve-se ficar atento à freqüência da presença populacional das espécies inadequadas ao ambiente urbano. Sempre que possível, a substituição dessas espécies deve ser considerada, partindo primariamente da possibilidade de substituí-las por espécies regionais e nativas, que possam atender além da estética, a sustentação ampla da fauna e da flora. Caso não exista a possibilidade de se obter espécies regionais nativas regionais e brasileiras, substitui-se por espécies exóticas aclimatadas e adequada as condições físicas da cidade, mas sempre procurando controlar a freqüência populacional da dominância arbórea no ambiente (ELETROPAULO, 1995 apud DANTAS; SOUZA, 2004).

Índice de diversidade de Shannon-Wiener (H'), utilizado para medir a diversidade dos dados coletados no ambiente urbano, foi de 1,89. Este valor foi inferior quando comparado a outros estudos realizados como o de Silva Filho e Bortoleto (2005), que encontraram diversidade superior a 3,0 para seis setores da arborização viária de Águas de São Pedro - SP, e índice de 2,91 para oito zonas de vegetação homogêneas para 0 município de Assis, SP. Meneguetti (2003) obteve 2,61 para a Orla de Santos-SP. Para o Sul do Brasil, trabalhos têm demonstrado valores de índices de diversidade um pouco menores aos comparados com os da região sudeste. Em Lages-SC, Santos et al., 2013 constataram baixo número de espécies para 32 ruas amostradas no centro da cidade. A baixa diversidade resultou em um índice de H' de 1,25 , ligeiramente inferior ao encontrado neste trabalho. Em São Vicente do Sul- RS, a baixa diversidade foi verificada por Rodrigues e Copatti (2009) em três escolas presentes no ambiente urbano da cidade, resultando de H' de 1,19 a 0,69. $\mathrm{O}$ autor atribui a baixa diversidade decorrente da ausência da participação da comunidade e aos fracassos dos plantios em ambiente urbano. Em Cachoeira do Sul- RS, município localizado aproximadamente $96 \mathrm{Km}$ de Santa Cruz do Sul, Lindenmaier e Santos (2008) encontraram diversidade maior, resultando em $\mathrm{H}^{\prime}$ de 3,86 , 
resultado da amostragem em 21 praças da área urbana da cidade.

A diversidade do ambiente urbano é um importante indicador da qualidade ambiental. Quando alta, em um ecossistema natural ou urbano, é capaz de promover uma maior estabilidade dos sistemas ecológicos, propiciando o surgimento de novos hábitat e recursos alimentares para fauna e flora regional, propiciando interações entre os indivíduos mais complexas e dificultando o aparecimento de doenças. Todos estes aspectos podem também estar relacionados com o desenvolvimento sócioeconômico da população, servindo, portanto, como ferramenta para tomada de decisão por partes dos órgãos responsáveis pela gestão urbana (GUZZO, 1991; CAVALHIERO, 1995 apud MENEGHETTI; COUTO, 2003).

Mesmo com moderada diversidade arbórea, o ambiente urbano analisado possui também espécies mal distribuídas, uma vez que apenas cinco espécies correspondem maior parte da população analisada no bairro centro de Santa Cruz do Sul. Normalmente, alguns autores como Grey e Deneke (1978), recomendam que a freqüência das espécies abundantes não ultrapasse $10 \%$ a $15 \%$ do total da comunidade, já outros como Santamour Júnior (1990), partem do pressuposto de que se plante no máximo $10 \%$ de indivíduos para cada espécies e que, e da mesma forma, não se ultrapassem $20 \%$ de indivíduos para o mesmo gênero e 30\% indivíduos por família botânica.

Estas freqüências sugeridas estão diretamente relacionadas às medidas de precauções fitossanitárias, visando impedir que futuras doenças se propaguem com facilidade por todos os indivíduos da população. Conseqüentemente, tais valores sugeridos propiciam uma manutenção da longevidade das espécies o mais próxima possível da faixa de sobrevivência em ambiente natural
(ALVAREZ; LIMA， 2004; MENEGHETTI; COUTO, 2003).

As padronizações de freqüências sugeridas pelos autores, neste caso estabelecidas de 10 a $15 \%$ de indivíduos por espécie, não foram de fato diagnosticadas na área urbana avaliada. $\mathrm{O}$ aumento da predominância de muitos indivíduos distribuídos em poucas espécies pode ter sido decorrente de ações cumulativas dos anos anteriores da administração pública, responsável pelo planejamento da arborização, em conjunto com o crescimento do centro da cidade.

\section{Levantamento das espécies produzidas no horto florestal municipal}

Conforme os dados demonstrados na Tabela 2, a produção do Horto florestal, no ano de 2009, foi de 31.170 mudas, sendo 2.240 mudas enraizadas a campo, pós transplante, representando $7,20 \%$ do valor total, e 28.930 mudas em embalagens, dispostas em canteiro, correspondendo a 92,80\%.

Das 31.170 mudas produzidas, 19.540 são nativas do Brasil, correspondendo a $62,6 \%$ da produção distribuída em 36 espécies nativas. A produção exótica divide-se em 21 espécies exóticas, o que corresponde a 11.630 mudas, ou seja, 37,4\% do total produzido. A média aritmética de produtividade anual para o ano de 2009 foi de 542,8 indivíduos produzidos por espécie nativa. O ponto de corte para a produção mínima das espécies nativas foi de 271,4 indivíduos por espécie. A abundância das espécies possivelmente tem relação com a popularidade e procura das essências pela comunidade municipal, bem como facilidade de produção e pega no viveiro, causando, portanto, influência no valor das médias apresentadas para no ano corrente avaliado.

ARBORIZAÇÃO DE VINTE QUARTEIRÕES AMOSTRADOS... 
Conforme apresentado na tabela 2, 12 espécies resumem-se à produção de 14.500 essências nativas, ou $74,2 \%$ do total produzido, sendo distribuídas nas seguintes espécies: Ingá verde (Inga marginata), Sibipiruna (Caesalpinia peltophoroides), Açoita cavalo (Luehea divaricata), Pitangueira (Eugenia uniflora), Ingá amarelo (Inga uruguensis), Angico vermelho (Parapiptadenia rígida), Ipê roxo (Tabebuia avellanedae), Cereja (Myrciaria ciliolata), Ipê amarelo (Tabebiua chrysotricha), Cedro (Cedrela fissilis), Canafístula (Peltophorum dubium) e Araçás (Psidium cattleianum). Vale ressaltara que as essências frutíferas nativas ganham destaque na produção do horto municipal, no entanto, muitas delas não estão presentes na arborização urbana.

Tabela 2. Espécies florestais produzidas no Horto Florestal de Santa Cruz do Sul, RS, 2009

\begin{tabular}{|c|c|c|c|c|}
\hline Nome Comum (1) & Nome científico & Família & Origem (2) & Qtd. \\
\hline Araçá amarelo & Psidium cattleianum Sabine. & Myrtaceae & N/Brasil & 600 \\
\hline Araçá vermelho & Psidium cattleianum Sabine. & Myrtaceae & N/Brasil & 600 \\
\hline Acácia mimosa & Acacia podalyriaefolia A. Cunn. & Leg.-Mimosoideae & E/Austrália & 200 \\
\hline Açoita cavalo & Luehea divaricata Mart. & Tiliaceae & N/Brasil & 1.400 \\
\hline Angico vermelho & Parapiptadenia rigida Brenan. & Leg.-Mimosoideae & N/Brasil & 980 \\
\hline Aroeira pimenta & Schinus terebinthifolius Raddi. & Anacardiaceae & N/Brasil & 200 \\
\hline Aroeira salsa & Schinus molle L. & Anacardiaceae & N/Brasil & 190 \\
\hline Araticum & Rollinia rugulosa Schl. & Annonaceae & N/Brasil & 450 \\
\hline Araucária & Araucaria angustifólia (Bertol.) & Araucariaceae & N/Brasil & 50 \\
\hline Azaléia & Rhododendron simsii Planch. & Ericaceae & E/China & 130 \\
\hline Barba timão & Stryphnodendron adstringens (Mart.) & Fabaceae & N/Brasil & 50 \\
\hline Camboatá verm. & Cupania vernalis Camb. & sapindaceae & N/Brasil & 280 \\
\hline Canela tempero & Cinnamomum zeylanicum (Brey). & Lauraceae & E/Ceilão & 300 \\
\hline Canafístula & Peltophorum dubium Taub. & $\begin{array}{l}\text { Leg.- } \\
\text { Caesalpinoideae }\end{array}$ & N/Brasil & 600 \\
\hline Caroba & Jacaranda micrantha Cham. & Bignoniaceae & N/Brasil & 140 \\
\hline Cedro & Cedrela fissilis Vell. & Meliaceae & N/Brasil & 700 \\
\hline Cereja & Myrciaria ciliolata Camb. & Myrtaceae & N/Brasil & 900 \\
\hline Chal-chal & Allophylus edulis (ST Hil.) & Sapindaceae & N/Brasil & 450 \\
\hline Chuva de ouro & Cassia fistula L. & $\begin{array}{l}\text { Leg.- } \\
\text { Caesalpinoideae }\end{array}$ & E/Ásia & 100 \\
\hline Cinamomo & Melia azedarach L. & Meliaceae & E/Austrália & 150 \\
\hline Corticeira do banhado & Erythrina crista-galli L. & $\begin{array}{l}\text { Leg.- } \\
\text { Papilionoideae }\end{array}$ & N/Brasil & 100 \\
\hline Extremosa & Lagerstroemia indica L. & Lithraceae & E./China & 240 \\
\hline Ficos benjamin & Ficus benjamina L. & Moraceae & E/Índia & 30 \\
\hline Flamboyant & Delonix regia Rafin. & $\begin{array}{l}\text { Leg.- } \\
\text { Caesalpinoideae }\end{array}$ & E/ Madg. & 130 \\
\hline Fruta do conde & Annona squamosa $\mathrm{L}$. & Annonaceae & E/Am. Cent. & 190 \\
\hline Guajuvira & Patagonula americana L. & Boraginaceae & N/Brasil & 110 \\
\hline Guabijú (E) & Myrcianthes pungens (O. Berg) & Myrtaceae & N/Brasil & 200 \\
\hline Guatambu & $\begin{array}{l}\text { Balfourodendron } \\
\text { (Engler) }\end{array}$ & Rutaceae & N/Brasil & 100 \\
\hline Guapuruvú & Schizolobium parahyba (vell) Blake. & $\begin{array}{l}\text { Leg.- } \\
\text { Caesalpinoideae }\end{array}$ & N/Brasil & 200 \\
\hline Grevílea anã & Grevillea banksii R. Br. & Proteaceae & E/Austrália & 200 \\
\hline Grevílea robusta & Grevillea robusta A. Cunn. & Proteaceae & E/Austrália & 50 \\
\hline Goiaba & Psidium guajava L. & Myrtaceae & N/Brasil & 650 \\
\hline Hibisco & Hibiscus rosa-sinensis Linn. & Malvaceae & E/Ásia & 650 \\
\hline Ingá verde & Inga marginata Willd & Leg.-Mimosoideae & N/Brasil & 3.700 \\
\hline Ingá amarelo & Inga uruguensis Hooker et Arnott & Leg.-Mimosoideae & N/Brasil & 1.000 \\
\hline Ipê amarelo & Tabebiua chrysotricha (Mart.Ex DC) & Bignoniaceae & N/Brasil & 760 \\
\hline
\end{tabular}




\begin{tabular}{|c|c|c|c|c|}
\hline Ipê felpudo & Zeyheria tuberculosa Vell. Bur & Bignoniaceae & N/Brasil & 50 \\
\hline Ipê roxo & Tabebuia avellanedae Lor. Ex Griseb & Bignoniaceae & N/Brasil & 960 \\
\hline Jacarandá mim. & Jacaranda mimosaefolia D.Don & Bignoniaceae & E/Argentina & 350 \\
\hline Jabuticaba & Plinia trunciflora (O. Berg) & Myrtaceae & N/Brasil & 270 \\
\hline Jambolão & Syzygium euminni (L.) & Myrtaceae & E/Ásia & 270 \\
\hline Louro & Laurus nobilis Cav. & Lauraceae & E/Ásia & 100 \\
\hline Manduirana & Senna macranthera (Collad.) Irwin. & Leg.-Mimosoideae & N/Brasil & 80 \\
\hline Maria preta & Diatenopteryx sorbifolia Radlk. & Sapindaceae & N/Brasil & 250 \\
\hline Nêspera & Eriobptrya japonica (Thumb.) & Rosaceae & E/China & 200 \\
\hline Pau Brasil & Caesalpinia echinata Lam. & $\begin{array}{l}\text { Leg.- } \\
\text { Caesalpinoideae }\end{array}$ & N/Brasil & 180 \\
\hline Pau ferro & Caesalpinia ferrea Mart. & $\begin{array}{l}\text { Leg.- } \\
\text { Caesalpinoideae }\end{array}$ & N/Brasil & 350 \\
\hline Pau sangue & Pterocarpus rohrii Vahl & Fabaceae & N/Am. Sul & 40 \\
\hline Pitanga & Eugenia uniflora L. & Myrtaceae & N/Brasil & 1.000 \\
\hline Pata de vaga & Bauhinia forficata Link. & $\begin{array}{l}\text { Leg.- } \\
\text { Caesalpinoideae }\end{array}$ & N/Brasil & 200 \\
\hline Pingo de ouro & Duranta repens L. & Verbenaceae & E/México & 5.000 \\
\hline Primavera & Brunfelsia uniflora D.Don. & Solanaceae & N/Brasil & 150 \\
\hline Romã & Punica granatum L & Punicaceae & E/Ásia & 90 \\
\hline Sibipiruna & Caesalpinia peltophoroides Bhent & $\begin{array}{l}\text { Leg.- } \\
\text { Caesalpinoideae }\end{array}$ & N/Brasil & 1.900 \\
\hline Tarumã & Vitex megapotamica (Spreng.) & Lamiaceae & N/Brasil & 50 \\
\hline Tipuana (E) & Tipuana tipu (Benth.) & $\begin{array}{l}\text { Leg.- } \\
\text { Papilionoideae }\end{array}$ & E/Argentina & 2.000 \\
\hline Timbaúva (E) & Enterolobium contortisiliquum Vell. & Leg.-Mimosoideae & N/Brasil & 300 \\
\hline Uva japonesa (R) & Hovenia dulcis Thumb. & Rhamnaceae & E/Japão & 600 \\
\hline
\end{tabular}

(1) (E)= Muda em embalagem; (R)= Enraizada a campo. (2) E= Exótica; N= Nativa.

Outras 24 espécies de essências florestais nativas correspondem ao restante da produção levantada, 25,8\% do total produzindo, sendo distribuída entre as seguintes espécies: Araticum (Rollinia rugulosa), Chal-chal (Allophylus edulis), Pau ferro (Caesalpinia ferrea), Timbaúva (Enterolobium contortisiliquum), Jabuticaba (Plinia trunciflora), Maria preta (Diatenopteryx sorbifolia), Aroeira pimenta (Schinus terebinthifolius), Guabijú (Myrcianthes pungens) Pata de vaca (Bauhinia forficata), Guapuruvú (Schizolobium parahyba ), Aroeira salsa (Schinus molle), Pau Brasil (Caesalpinia echinata), Primavera (Brunfelsia uniflora), Caroba (Jacaranda micrantha ), Guajuvira (Patagonula americana ), Corticeira do Banhado (Erythrina crista-galli), Guatambu (Balfourodendron riedelianum), Manduirana (Senna macranthera), Araucária (Araucaria angustifolia), Barbatimão (Stryphnodendron adstringens), Ipê felpudo (Zeyheria tuberculosa), Pau sangue (Pterocarpus rohrii), e Tarumã (Vitex megapotamica).

Os valores de baixa produtividade de algumas essências nativas podem estar relacionados com a dificuldade em se estabelecer uma propagação sexuada das espécies que não são populares, em que a procura é conseqüentemente menor devido ao desconhecimento das espécies por parte da comunidade em geral, bem como as dificuldades de se produzir no viveiro.

Quanto às essências florestais exóticas foi constatada média aritmética de 553,8 indivíduos por espécie. O ponto de corte para a produção mínima foi determinado pela metade da média, ou seja, 277 indivíduos por espécie produzida. 
Destacam-se entre as mudas exóticas produzidas, espécies de jardins ou ornamentais como o Pingo de ouro (Duranta repens), e outras essências florestais que superaram a média aritmética, tais como: Tipuana (Tipuana tipu) (TABELA 2). Pingo de ouro (Duranta repens) encontra-se em grande quantidade no sistema por ser uma muda barata, de grande procura para ajardinamento. Suas características biológicas também favorecem a sobrevivência a climas temperados. Por serem consideradas mudas pequenas, de fácil cultivo por estaquia e de grande popularidade, seu predomínio no sistema produtivo é evidente, uma vez que também necessita de pouco espaço para a produção. A tipuana (Tipuana tipu) está presente em grande quantidade no sistema, por ser também considerada uma espécie popular, principalmente para a cidade, uma vez que constitui o túnel verde da região central, sendo que a presença em grandes quantidades de mudas pode também representar uma possível fonte para a manutenção do túnel arbóreo da cidade. Por possuir uma característica favorável de adaptação à região, tendo vigor e crescimento rápido, e ser uma espécie fácil para se propagar através de propagação sexuada, esta espécie acaba aparecendo como a segunda exótica mais abundante produzida no sistema.

Observa-se ainda na tabela 2, que Uva japonesa (Hovenia dulcis), Goiaba (Psidium guaja) e Hibisco (Hibiscus rosa-sinensis), também se destacam como abundantes no processo produtivo, correspondendo às quantidades de 600, 650 e 650 mudas no sistema. Vale lembrar que Uva do Japão (Hovenia dulcis) é uma espécie invasora de ambientes silvestres, causando grandes problemas ambientais por competir com espécies nativas em ambiente natural (RODOLFO et al., 2007). Existe, portanto, uma grande possibilidade destas mudas serem eliminadas do processo produtivo pelas questões ambientais, uma vez que as mesmas encontram-se acumuladas no sistema de produção do Horto Florestal, sendo enraizadas a campo. O plano diretor de arborização urbana prevê erradicação desta espécie no município de Santa Cruz do Sul (LEI MUNICIPAL Nº 6.447/2012)

Indivíduos de Hibisco (Hibiscus rosa-sinensis) parece representar um caso à parte, uma vez que é muito difundida e de fácil cultivo, deixa de ser atraente e procurada pela população. Já espécimes como o Jacarandá mimoso (Jacaranda mimosaefolia), e Canela tempero (Cinnamomum zeylanicum), possuem produção consistente devido a sua popularidade e procura pela comunidade, sendo as duas, comumente encontradas na arborização de vias públicas do município.

Neste caso, a demanda e o preço comercializado pelo horto fazem com que algumas essências permaneçam em baixa quantidade no processo produtivo, como é o caso de Jambolão (Syzygium euminni), Extremosa (Lagerstroemia indica), Acácia mimosa (Acacia podalyriaefolia), Grevilea anã (Grevillea banksii), Nêspera (Eriobptrya japonica ), Fruta do conde (Annona squamosa), Cinamomo (Melia azedarach), Azaléia (Rhododendron simsii), Flamboyant (Delonix regia), Chuva de ouro (Cassia fistula), Louro (Laurus nobilis ), Romã (Punica granatum), Grevilea robusta (Grevillea robusta) e Ficos benjamin (Ficus benjamina).

Grevílea robusta (Grevillea robusta) é considerara uma espécie pouco apreciada pela comunidade pelo seu efeito caducifólio intenso. É, portanto uma das espécies exóticas menos produzidas e menos procurada no horto florestal municipal. Tudo indica que, exemplares de Extremosa (Lagerstroemia indica) não estão sendo mais tão procurados para a substituição e manutenção dos passeios públicos em 
que boa parte da população se faze presente no passeio público da cidade.

\section{Aproveitamento das essências florestais na arborização}

Ruschel e Leite (2002), inventariaram a arborização urbana em Lajeado, município localizado à cerca de $60 \mathrm{Km}$ de Santa Cruz do Sul. Conforme os dados dos autores houve predomínio similar de composição de espécies exóticas mais abundantes no levantamento, em que estiveram presentes, em maior número, Extremosa (Lagerstroemia indica), Ligustro (Ligustrum japonicum); no entanto para Santa Cruz do Sul, a ocorrências de espécies nativas $(8,9 \%)$ na área amostrada foi menor quando comparado aos dados de Lajeado (33,3\%).

Lei municipal $n^{0}$ 3.978/03 estabelece as normas de manejo, proteção e conservação da arborização no município de Santa Cruz do Sul, RS. Esta lei institui em seu artigo 11, inciso VII a autorização de poda drástica em espécies com princípios tóxicos provocadas por Aroeiras do gênero Schinus, e da espécie Ligustro (Ligustrum japonicum). No artigo $15, \S 1^{\circ}$, a mesma legislação estabelece substituição da espécie Ligustrum japonicum por outra espécie em funções das reações alérgicas que o pólen causa em parte da população.

No Rio Grande do Sul, as espécies exóticas de Ligustro (Ligustrum japonicum) e (Ligustro lucidum) estão normalmente associada a problemas alérgicos denominado de "Polinose". A poda ou supressão de Ligustro japonicum é legalmente autorizada em alguns municípios gaúchos como Santa Cruz do Sul, São Paulo das Missões Santo Ângelo e Giruá (BRUN et al., 2008). No entanto, para Santa Cruz do Sul, área de estudo, atualização da lei $\mathrm{n}^{\circ}$ 3.978/03 deve ser realizada com a finalidade de incluir também a supressão legal e substituição da outra espécie Ligustro (Ligustro lucidum) inventariada na região central. Casos de Polinose afetam preferencialmente a população urbana das cidades gaúchas, por ter efeito endêmico preferencial em latitudes maiores que $25^{\circ} \mathrm{S}$, e com condições climáticas de continentalidade (SBAI, 2003 apud BRUN et al., 2008).

Algumas ações como a diminuição da freqüência de espécies abundantes e o aproveitamento da riqueza de espécies produzidas pelo próprio município, são capazes de aumentar a freqüência de espécies nativas e conseqüentemente a diversidade e qualidade do ambiente urbano. Espécies como Araçá (Psidium cattleianum Sabine), Araticum (Rollinia rugulosa Schl.), , Barba timão (Stryphnodendron adstringens), Caroba (Jacaranda micrantha Cham.), Cereja (Myrciaria ciliolata Camb.), Chal-chal (Allophylus edulis (ST Hil.)), Ingá amarelo (Inga uruguensis Hooker et Arnott), Ingá verde (Inga marginata Willd), Ipê amarelo (Tabebiua chrysotricha (Mart.Ex DC)), Ipê roxo (Tabebuia avellanedae Lor. Ex Griseb), Manduirana (Senna macranthera (Collad.) Irwin); Pau ferro (Caesalpinia ferrea Mart.), Pitanga (Eugenia uniflora L.), Sibipiruna (Caesalpinia peltophoroides Bhent), Tarumã (Vitex megapotamica (Spreng.)), Guabijú (Myrcianthes pungens (O. Berg)), Guajuvira (Patagonula americana L.) podem ser aproveitadas no enriquecimento do ambiente urbano, substituindo espécies problemáticas como as do gênero Ligustrum.

Apenas nove espécies nativas foram encontradas nos passeios públicos, três delas acima de um por cento de freqüência, seis delas abaixo do mesmo percentual, entre elas estão: Aroeira vermelha (Schinus terebinthifolius Raddi) 0,21\% (3), Canafístula (Peltophorum dubium Taub.) 0,35\% (5), Chal-chal (Allophylus edulis (ST Hil.) 0,07\% 
(1), Ingá (Inga marginata Willd) 2,1\% (30), Ipê amarelo (Tabebiua chrysotricha (Mart.Ex DC)) 1,28\% (18), Ipê roxo (Tabebuia avellanedae Lor. Ex Griseb) 0,41\% (6), Manduirana (Senna macranthera (Collad.) Irwin) 2,27\% (32), Pitanga (Eugenia uniflora L) $0,14 \%$ (2) e Sibipiruna (Caesalpinia peltophoroides Bhent.) 0,41\% (6).

Estes valores indicam não só a potencialidade produtiva do sistema municipal, como também a necessidade do uso e aplicação das essências na própria arborização da cidade, uma vez que a aplicação de espécies nativas no ambiente urbano é capaz de diminuir a freqüência indicada pela ISA (International Society of Arboriculture) sobre as espécies abundantes e aumentar a disponibilidade variada de alimentos à fauna regional, promovendo a conservação das espécies remanescentes na malha viária. Além disso, o plantio de espécies nativas contribui com uma estética mais dinâmica e heterogênea para o ambiente urbano, e o aumento da riqueza de espécies introduzidas pode servir como fonte importante para trabalhos de educação ambiental e valorização do tema pela população local.

\section{CONCLUSÕES}

Os resultados obtidos através do inventariamento da produção de essências florestais no horto municipal da cidade, em contraste com a análise da arborização da região central do município, revelaram a necessidade de um melhor aproveitamento das essências produzidas na própria arborização da cidade. Das essências florestais produzidas no horto municipal, 62,6\% são nativas e muitas excederam a média aritmética do total de indivíduos produzidos por espécie, indicando potencialidade para o aproveitamento na manutenção e substituição periódica de árvores viárias da região amostrada. Estes valores revelam boa capacidade de suporte produtivo do horto municipal, em não somente atender à comunidade, mas também servir de auxílio na manutenção e aumento da qualidade ambiental na arborização da cidade, que possui $83,4 \%$ do total de árvores amostradas distribuídas em apenas cinco espécies exóticas.

$\mathrm{Na}$ realidade atual, foi possível verificar a necessidade de uma reformulação da arborização na região central de Santa Cruz do Sul, principalmente através da substituição gradual das espécies exóticas, que ultrapassaram os valores de 15\% de abundância. Neste caso, é interessante iniciar as substituições através dos indivíduos que contribuem com o desconforto ambiental, causando alergia em épocas de floração, como é o caso de Ligustro (Ligustrum lucidum). Espécies invasoras presentes no sistema produtivo do horto florestal, como é o caso de Uva-japonesa (Hovenia dulcis) devem ser erradicadas. Registros desta espécie já foram feitos para o cinturão verde da cidade, área de conservação ambiental, indicando potencial comprometimento de espécies de nativas. 
ALVAREZ, I. A.; LIMA, A. M. L. P. Qualidade do espaço Verde urbano: uma proposta de índice de avaliação. Dissertação (Mestrado). Universidade de São Paulo, Escola Superior de Agricultura Luiz de Queiroz, 2004.

APG III. An update of the Angiosperm Phylogeny Group classification for the orders and families of flowering plants: APG III. Botanical Journal of the Linnean Society, v. 161, p. 105-121, 2009.

BACKES, P.; IRGAN, B. Árvores do sul: Guia de Identificação \& Interesse Ecológico. 1. ed. Rio Grande do Sul: Instituto Souza Cruz, 2002.

BIONDI, D.; LEAL, L. Caracterização das plantas produzidas no horto municipal da Barreirinha - Curitiba / PR. Revista da Sociedade Brasileira de Arborização Urbana, v. 3, n. 2, p. 20-36, 2008.

BRUN, F. G. K.; FUCHS, R. H.; BRUN, E. J.; ARAÚJO, L. E. B. Legislações municipais do Rio Grande do Sul referentes à arborização urbana - estudo de casos. Revista da Sociedade Brasileira de Arborização Urbana, v. 3, n. 3, p. 44-64, 2008.

COELHO, R. M. P. Fundamentos em Ecologia. Porto Alegre: Artes Médicas, 2000.

CORRÊA, L. R. Relação entre o critério socioeconômico e parâmetros ecológicos relativos à arborização viária de canoas, Brasil. Pesquisas, Botânica, n. 34, p. 303-318, 2006.

DANTAS, I. C.; DE SOUZA, C. M. C. Arborização Urbana na Cidade de Campina Grande - PB: Inventário e Suas Espécies. Revista de Biologia e Ciências da Terra, Paraíba, v. 4, n. 2, setembro, 2004.

GREY, G. W.; DENEKE, F. J. 1978. Urban forestry. New York: John Wiley, 1978 279p.

IBGE. Censo demográfico 2007: Banco de dados agregados do IBGE. Disponível em: <http://www.ibge.gov.br/home/estatistica/populacao/contagem2007/> Acessado em: 02 jan. 09.

LINDENMAIER, D.S. \& SANTOS, N.O. Arborização urbana das praças de Cachoeira do Sul - RS Brasil: fitogeografia, diversidade e índices de áreas verdes. Pesquisas, Botânica, São Leopoldo, n. 59. p. 307320, 2008. 
MARTINS, L. M.; MAIA, J. C.; BRITO, J. S. Os conflitos existentes entre a arborização e os equipamentos urbanos no centro de Terezina,PI. II Congresso de Pesquisa e Inovação da Rede Norte Nordeste de Educação Tecnológica, João Pessoa, PB, 2007.

MENEGHETI, G.; COUTO. H. T. Z. Estudo de dois métodos de amostragem para inventário da Arborização de ruas dos Bairros Orla Marítima do Município de Santos, SP. Dissertação (Mestrado). Universidade de São Paulo, Escola de Agricultura Luiz de Queiroz, 2003.

PREFEITURA MUNICIPAL DE SANTA CRUZ DO SUL. 2009. Apresenta informações gerais sobre o município. Disponível em: < http://www.pmscs.rs.gov.br/index.php> Acessado em: 02 jan. 09.

PUTZKE, JAIR. Chave para espécies de árvores encontradas no Vale do Rio Pardo. Do autor, 2003.

PUTZKE, JAIR. Chaves para a identificação de pinophyta (Gimnospermas). Do autor, 2003.

RODOLFO, A. M.; CÂNDIDO-JR, J. F.; TEMPONI, L. G.; GREGORINI, M. Z. Citrus auratium L. (LARANJA APEPU) e Hovenia dulcis (UVA-DO-JAPÃO): espécies exóticas invasoras da Trilha do Poço Preto, Parque Nacional do Iguaçu - Paraná - BR. UNIOESTE: VXII Semana da Biologia, 2007.

RODRIGUES, C. A. G.; BEZERRA, B. C.; ISHII, I. H.; CARDOSO, E. L.; SORIANO. B. M. A.; OLIVEIRA, H. Arborização Urbana e Produção de Essências Florestais Nativas em Corumbá, MS. Corumbá: Embrapa, INSS 1517-1981, Dez. 2002.

RODRIGUES, L. S.; COPATTI, C. E. Diversidade arbórea das escolas da área urbana de São Vicente do Sul/RS. BIODIVERSIDADE PAMPEANA. PUCRS, Uruguaiana, v. 7 n. 1, p. 7-12, 2009.

RUSCHEL, D.; LEITE, S. L. DE C. Arborização Urbana em uma área da cidade de Lajeado, Rio Grande do Sul, Brasil. Caderno de pesquisa sério Biologia. 1677-5600, 2002.

SANCHOTENE, M. C. C. (coord). Plano diretor de vias públicas. Porto Alegre: Secretaria Municipal do Meio Ambiente, 2000. 203 p.

SANTAMOUR JÚNIOR, F.S. Trees for urban planting: diversity uniformity, and common sense. In: METRIA CONFERENCE, 7., 1990, Lisle. Proceedings. Lisle:. p.57-66, 1990.

SANTOS, E. M.; SILVEIRA, B. D-B.; SOUZA, A. C.; SCHMITZ, V.; SILVA, A. C.; HIGUCHI, P. Análise quali-quantitativa da arborização urbana em Lages, SC. Revista de Ciências Agroveterinárias. Lages, v.12 n.1, p. 59-67, 2013 
SANTOS, S. A. T.; FONSECA, E. M. B.; REZENDE, A. P. S. Programa de Compatibilização da arborização com a rede de distribuição de energia aérea. Belo Horizonte: Cemig, 1994.

SANTOS, N. R.; TEIXEIRA, I. R. Arborização de vias públicas: Ambiente x Vegetação. 1. ed. Rio Grande do Sul: Instituto Souza Cruz, 2001. 135 p.

SILVA, A. G. Arborização urbana em cidades de pequeno porte: avaliação quantitativa e qualitativa. 2000. 150f. Dissertação (Mestrado em Ciências Florestais) - Universidade Federal de Viçosa, Viçosa, MG. 2000.

SILVA FILHO, D. F. DA.; BORTOLETO, S. Uso de indicadores de diversidade na definição de plano de manejo da arborização viária de Águas de São Pedro - SP. Revista Árvore, Viçosa-MG, v.29, n.6, p.973982, 2005.

SOBRAL, S.; JARENKOW, J. A.; BRACK, P.; IRGANG, B.; LAROCCA, J.; RODRIGUES, R. S. Flora Arbórea e Arborescente do Rio Grande do Sul, Brasil. RIMA: Novo Ambiente, 2006.

VIDAL, W. N.; VIDAL, M. R. R. Botânica organografia: Quadro Sinótico Ilustrado de Fanerógamos. 4. ed. Viçosa: UFV, 2000. 